\title{
A CLASSIFICATION OF CHEMICALLY SENSITIVE SEMICONDUCTOR DEVICES
}

\section{A A SAAMAN and P BERGVELD}

Department of Electrcal Engineering, Twente University of Technology, $P$ O Box 217, 7500 AE Enschede (The Netherlands)

(Received November 14, 1984, un revised form January 24, 1985, accepted February 19, 1985)

\begin{abstract}
A general scheme is presented for classifying chemically sensitive sem1conductor devices (CSSDs) CSSDs reported in the literature up to now, as well as related physicochemical phenomena, are briefly discussed and shown to fit in the scheme
\end{abstract}

\section{Introduction}

The impact of semiconductors on our present society would not have been realized without a thorough study of the (electro)chemical, physical, electronic and technological aspects of semiconductor materials and sem1conductor devices

This paper deals with Chemically Sensitive Semiconductor Devices (CSSDs), in which all four elements mentioned above are involved, the chemistry being the most relevant As a contribution to the rapidly developing CSSD field, an attempt is made here to classify them, for this purpose a general scheme is suggested emphazising analogies (1) between related fields of semiconductor research and (11) between CSSDs and their chemically insensitive electronic equivalents

The scheme will be presented below Next, CSSDs already reported in the literature are briefly discussed and it is shown how these fit in the proposed scheme, finally, the same is done for CSSD-related physicochemical phenomena

\section{Classification scheme for CSSDs}

The scheme is in fact a classification of XYS-systems, in which S stands for semiconductor, $\mathrm{X}$ is either a metal (electronic conductor), an electrolyte (1onic conductor) or a gas, and $\mathrm{Y}$ is related to the properties of an insulating layer on the semiconductor For $\mathrm{Y}$ three cases are distinguished 
(1) The insulating layer, if sufficiently thick and of good quality, will be an insulator in the traditional sense of the word In the following a layer of this type will be denoted as I

(11) When the thickness of the insulating layer is less than about $5 \mathrm{~nm}$, it is involved in electronic conduction processes associated with tunnelling phenomena Such a layer will be denoted as 1

(uil) The insulating layer may be absent

As a result the scheme incorporates autonomous and widely differing fields in semiconductor science, each of which has been intensively studied, but not necessarily from the viewpoint of chemical sensing, in this way the scheme also accounts for the versatility in applications and fundamental semiconductor research

Now it is not difficult to fill in the scheme with devices or device structures (Figs 1 and 2) Analogies should immediately be clear, of which three examples will be given

(1) MIS devices, realized either as MIS-capacitors or as MISFETs are characterized inter alia by their flat-band voltage $V_{\mathbf{F B}}$ or their threshold voltage $V_{T}$ Devices with chemically active gate metals may have a threshold voltage that is dependent on environmental parameters and can thus be used for chemical sensing purposes, nevertheless, the electronic operation

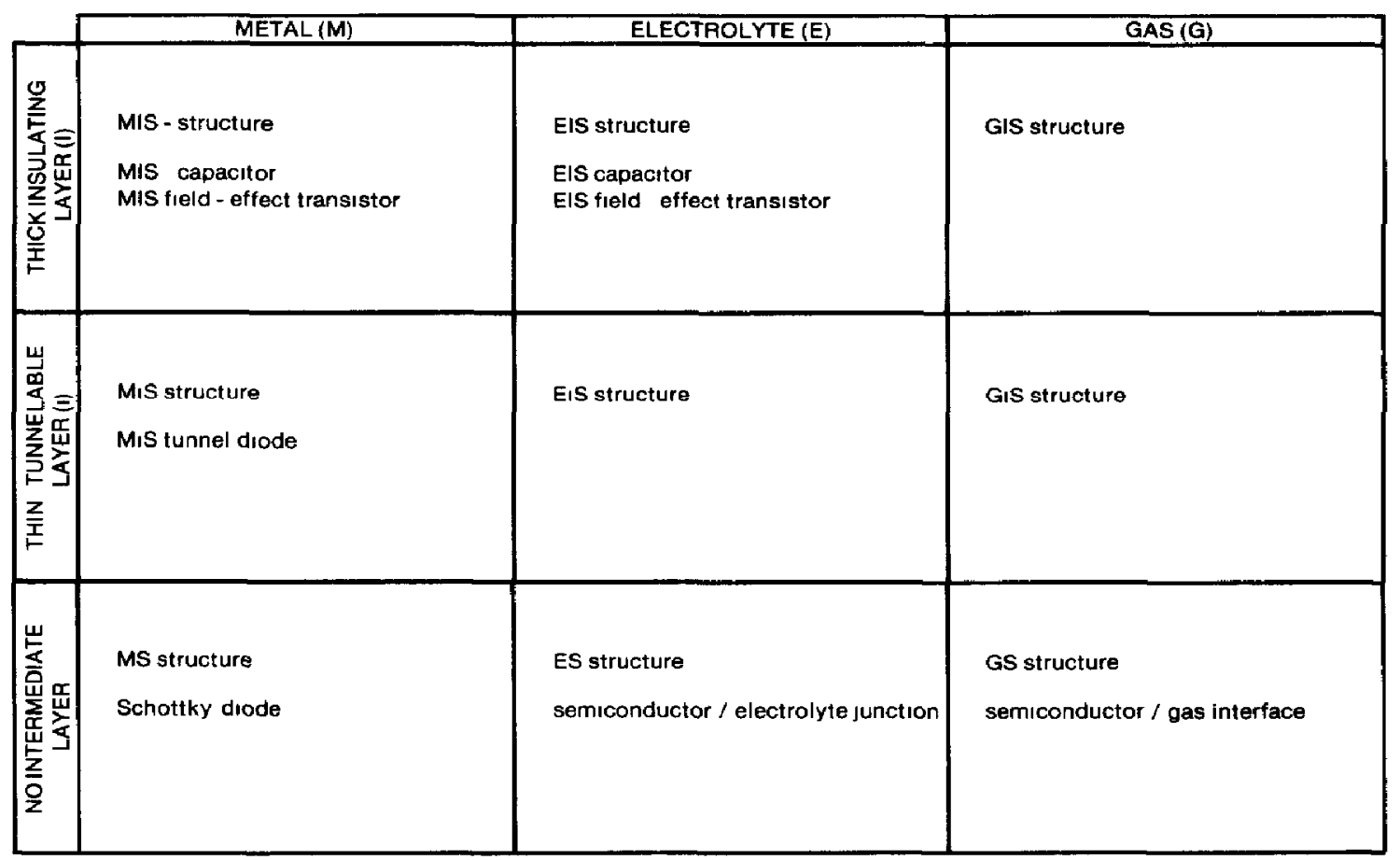

Fig 1 Scheme for the classification of Chemically Sensitive Semiconductor Devices (CSSDs) A CSSD is to be charactenzed as an XYS-structure in which S stands for sem1conductor, $X$ is a metal, an electrolyte or a gas, and $Y$ is related to the properties of an intermediate layer The elements of the matrix thus obtained are easily recognized as often well-studied fields in semiconductor research 


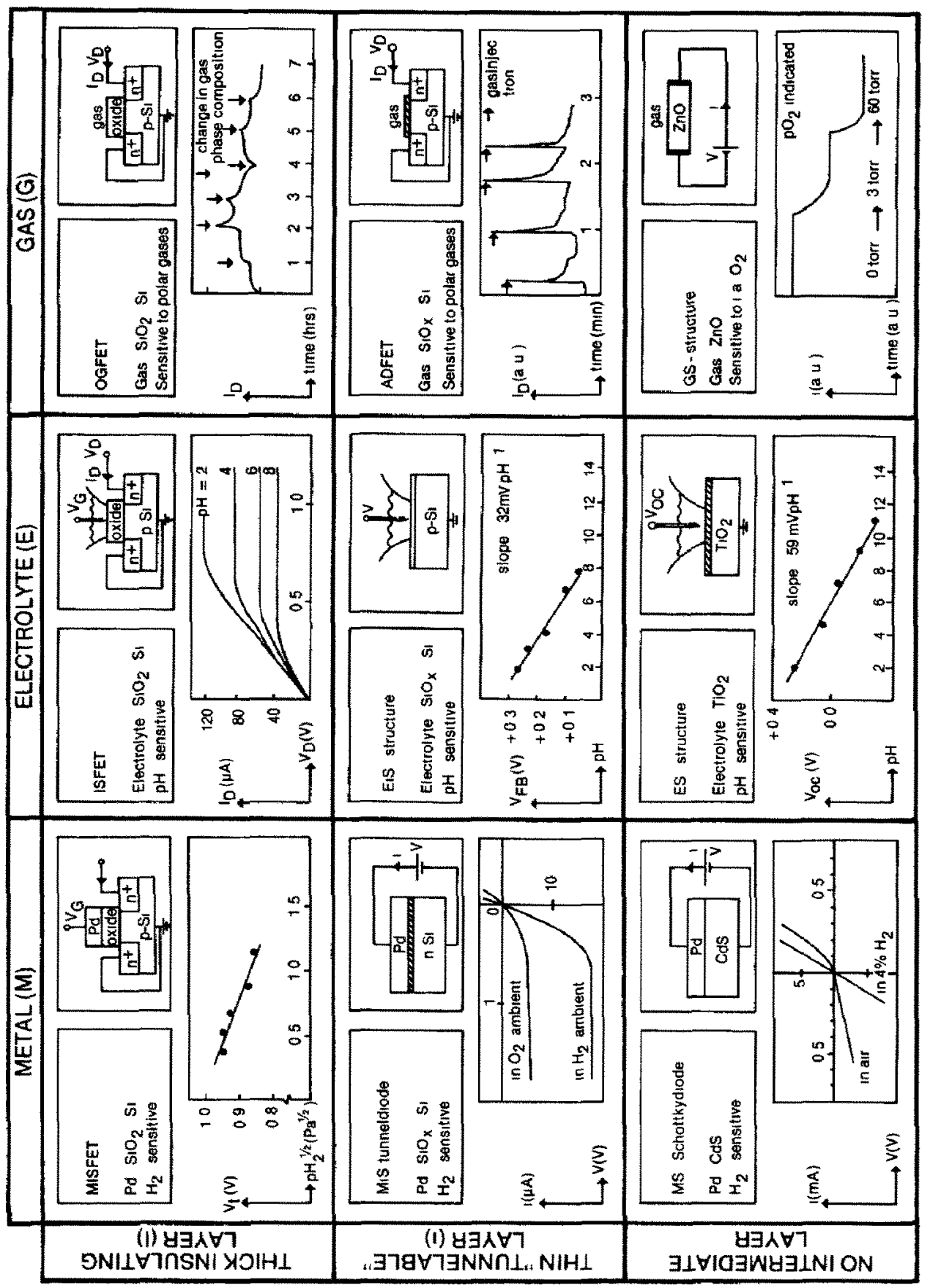

㝵骂

눙형

है क

范范

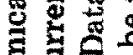

हี

今

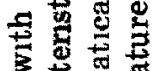

总忧焉

过获

Ð

놀

느용

-

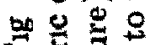

द 焉要

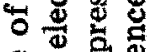

芒骂急

可嵒

总 雪

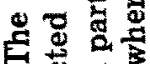

卷若范

o

5

政

녕호요

式

글 可苟

융용

焉苋

के

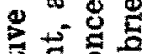

용용

के 형

을

뭉

ह $\vec{z}$

동 을

-

เै ह

ธี क

牙先

을

蛋

0 흥 ه bै 氖

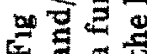


principles of these chemically sensitive devices are just the same as for the chemically insensitive MIS devices

EIS devices, mostly realized as ISFET structures, are also properly described by a chemically dependent threshold voltage, thus representing a clear example of the analogy between chemically sensitive MIS and EIS devices

(11) Another striking resemblance is demonstrated by the formulae describing the current-voltage characteristics of Schottky diodes (MS structures according to $\mathrm{Fig} 1$ ) and semiconductor/electrolyte structures (ES structures according to Fig 1) The former is given by [1]

$I=A T^{2} \exp \left(-\psi_{\mathrm{B}} / k T\right)[\exp (q V / k T)-1]$

whereas the latter appears in the literature as $[2,3]$

$I_{\phi_{\mathrm{E}}=0}=A T^{2} \exp \left(-q \phi_{\mathrm{B}} / k T\right)$

or

$I=I_{0}\left[\exp \left(q\left(\phi_{1}-\phi_{1}{ }^{0}\right) / k T\right)-1\right]$

In these formulae $I=$ current density, $A=$ Richardson's constant, $T=$ absolute temperature, $\psi_{\mathrm{B}}, \phi_{\mathrm{B}}=$ Schottky barrier energy and potential respectively, $k=$ Boltzmann's constant, $q=$ electronic charge, $V=$ voltage across the diode, $I_{\phi_{\mathrm{E}}=0}=$ current density at zero electrode potential and $\left(\phi_{1}-\phi_{1}{ }{ }\right)$ is the equivalent of $V$ in eqn (1)

The resemblance as expressed in the above formulae is a reflection of the well-known rectifying behaviour of both structures

(iil) The analogy between solid/electrolyte and solid/gas interfaces is still poorly clanfied, although the first steps in this very interesting field have already been taken an entire volume of Surface Science [4] is devoted to the so called 'non-traditional techniques in electrochemistry', in which information is obtained by studying the same solid surface with both (wet) electrochemical and (dry) solid state physics techniques So far, these investigations support the idea of an analogy between the columns headed 'Electrolyte' and 'Gas' in Figs 1 and 2

\section{Classification of sensor devices}

The elements of the matrix in Fig 1 will now be discussed from the viewpoint of CSSDs

(1) MIS-CSSDs

The 'trick' to be performed here is to replace the gate metal normally used (Al) by one that is known to possess chemical reactivity, such as the group VIII elements $\mathrm{Nl}, \mathrm{Pd}$ and $\mathrm{Pt}$ In this way devices sensitive to hydrogen [5], carbon monoxide [6], hydrogen disulphide [7] and ammonia [8] were 
realized The principle underlying the sensor operation of these devices is the formation of a dipole layer at the metal-insulator interface, the resulting voltage drop is measured as a flat-band voltage shift in either MIS capac1tance-voltage charactenstics or MISFETs and may equivalently be described by an envronmental dependence of the metal work function

The devices may be realized with single or multilayered dielectrics [9] In MIS capacitors with $\mathrm{Hg}$ as the metal, large flat-band voltage shifts were observed upon the addition of solid $\mathrm{Na}$ to the $\mathrm{Hg}$ [10] Of course, this flatband voltage shift is due to the formation of sodium amalgum, whose work function differs considerably from that of the pure mercury

\section{(ii) $M i S-C S S D s$}

Examples of these are the $\mathrm{Pd}^{2}-\mathrm{SiO}_{x}-\mathrm{S} 1$ hydrogen sensor of Zemel et al [11] and the $\mathrm{Al}-\mathrm{SiO}_{x}-\mathrm{Sl}$ molsture sensor of Duszak et al [12], where the insulator layers are no more than a few nanometres thick The former device is operated as a MiS-tunnel diode, whereas the latter is realized as a transistor-like structure, employing two interacting MiS-tunnel diodes

The fundamentals underlying both sensor structures are as yet not fully elucidated For the hydrogen sensor a chemically sensitive metal work function, thus modifying the MiS current-voltage characteristics, is suggested, extra current paths, involving tunnelling from surface states to the metal, are suggested by Zemel et al [11], but denied by others [13] No intensive studies on the mechanism of the above moisture sensor have been reported, but some kind of protonic involvement in the conduction processes in the silicon oxide layer is probable

It should be noted that the role of the insulator is quite different in both cases in the moisture sensor the oxide layer is likely to be involved in the chemical part of the sensing process In the hydrogen sensor, the oxide layer also plays a chemical role, but not in a sensing sense the main reason for its presence is to prevent the undesired formation of intermediate species, such as $\mathrm{Pd}_{2} \mathrm{Sl}$, whlle preserving the hydrogen sensitivity of the diode structure

A MiS-hydrogen sensor has also been realized with amorphous hydrogenated silicon [14]

\section{(ul) $M S-C S S D s$}

Finally, with no insulating layer left between the metal and the sem1conductor, we arrive at CSSDs based upon the chemical sensitivity of Schottky diodes In view of the foregoing discussion, it is not surprising to find that they consist of a catalytically active metal, almost exclusively Pd, and a semiconductor that must meet the following requirements (1) no undesired formation of intermediate species through reaction with the metal and (11) no Fermi level pinning

Hydrogen sensors based upon $\mathrm{Pd}-\mathrm{ZnO}$ [15], $\mathrm{Pd}-\mathrm{CdS}[16]$ and $\mathrm{Pd}-$ $\mathrm{TiO}_{2}[17]$ Schottky diodes have been reported It is commonly believed that their operation is properly described by the chemical sensitivity of the metal 
work function, thus modifying the Schottky diode current-voltage characteristics

Recently, a hydrogen-sensitive photodiode was also reported [18]

MIS-, MiS- and MS-based gas sensors are extensively discussed by Lundstrom [19]

(lv) EIS-CSSDs

An intensively studied class of CSSDs is formed by EIS devices, ISFETs [20] and Ion Controlled Diodes (ICDs) [21] fall into this category Both are field effect devices and employ the electrochemical properties of the insulator-electrolyte interface, basically its response to changes in the solution $\mathrm{pH}$ It now seems satisfactorily established $[22,23]$ that these devices operate through the so called site-dissociation model, in which the acid-base equilibria at the insulator-electrolyte interface are accounted for

Using standard double-layer theory, a relation between the solution $\mathrm{pH}$ and $\psi_{0}$, the potential at the insulator-electrolyte interface with respect to the bulk of the solution, was derived and experimentally verified [22, 23]

With respect to the insulator, the operation of these devices is greatly improved ( $l e$, nearer to Nernstian $\mathrm{pH}$ response, better selectivity, less drift) by using $\mathrm{Sl}_{3} \mathrm{~N}_{4}, \mathrm{Al}_{2} \mathrm{O}_{3}$ or $\mathrm{Ta}_{2} \mathrm{O}_{5}$ as an extra dielectric layer on top of the originally employed $\mathrm{SiO}_{2}$ layer [24]

\section{(v) CSSDs based upon ELS and ES structures}

The (electro)chemical properties of semiconductor-electrolyte structures and of structures with an ultrathin insulator between the two are seldom used for chemical sensing purposes The main interest in these systems is for solar energy conversion and fundamental research in materials science and on electron transfer mechanisms Besides, applications of these systems suffer from their low stability due to electrochemical and corrosion processes at the semiconductor-electrolyte interface A vast hterature [25] exists on the subject Nevertheless, observations on elemental and compound semiconductors have been made, that, at least in principle, indicate their possibilities for sensor applications

(a) The germanium/aqueous electrolyte interface was the first semiconductor/electrolyte system to be studied, starting with the work of Brattain and Garrett [26] Concerning the chemical sensor aspects, the $\mathrm{pH}$ of an aqueous solution could be measured provided hydrogen peroxide, $\mathrm{H}_{2} \mathrm{O}_{2}$, was present [27], a response of $60 \mathrm{mV} \mathrm{pH}{ }^{-1}$ was found Furthermore, an interaction was found between $\mathrm{Ge}$ electrodes and cupric [28] and iodide [29] 1ons However, these observations have not led to the development of useful chemical sensors

(b) The determination of the $\mathrm{pH}$ response of $\mathrm{Si}_{1}$ electrodes is usually influenced by the formation of a very thin silicon oxide film, this explains why Madou et al [30] found a non-Nernstian $\mathrm{pH}$ response of about $30 \mathrm{mV}$ $\mathrm{pH}^{-1}$ in the flat-band voltage determination This $\mathrm{pH}$ response is also found with $\mathrm{S}_{1} \mathrm{O}_{2}$-gated ISFETs, where the $\mathrm{S}_{1}$ surface is intentionally oxidized A 
carefully designed experimental procedure and an extrapolation method enabled Chazalvel [31] to obtain a Nernstian response for the rest potential $V_{x}$ in the current-voltage characteristics of a $\mathrm{n}-\mathrm{S} 1$-aqueous electrolyte interface

Wolkenberg [2] performed experiments on $\mathrm{Si}$-electrolyte interfaces with aqueous $\mathrm{Na}^{+}$and $\mathrm{K}^{+}$solutions, but the results are not encouraging from a sensor vewpoint $\mathrm{A}$ further point to be noticed is that ISFETs with only a $3 \mathrm{~nm}$ layer of gate oxide still behave as ISFETs, $l e$, normal transistor characteristics and a $30 \mathrm{mV}$ decade ${ }^{-1} \mathrm{pH}$ response are readily obtained over a surprisingly long period of time [32] This demonstrates that the use of the capacitive properties of E1S or ES systems is more promising than the use of their current-voltage behavour

(c) With compound semiconductor electrodes the situation is not much different from that for elemental semiconductors For the semiconducting metal oxıdes such as $\mathrm{ZnO}, \mathrm{H}^{+}$and $\mathrm{OH}^{-}$are the potential determining ions ( $\mathrm{p} \mathrm{d}_{1}$ ), in principle allowing their use in $\mathrm{pH}$ determinations Recently, the feasibility of $\mathrm{Pt}$, Ir and $\mathrm{Tr}$ oxides for $\mathrm{pH}$ determinations was discussed by Kinoshita and Madou [33] For CdS H${ }^{+}$and $\mathrm{HS}^{-}$were shown to be the $\mathrm{p} \mathrm{d} 1$ [34] One important application is that of the $\mathrm{pH}$ sensitivity of the $\operatorname{Ir} / \mathrm{Ir}_{x} \mathrm{O}_{y}$ electrode [35], which is used in such sophisticated devices as pacemakers [36]

It is interesting to notice that already in the earlier literature on this subject, the concept of a chemically sensitive semiconductor device is present often the semiconductor electrode is not simply a substitute for a noble metal electrode, but some kind of bipolar transistor structure is used In these so-called 'thin slice arrangements', the electrolyte replaces $e g$, the emitter of a bipolar transistor (the base and the collector are formed inside the semiconductor electrode) Ultimately, as was done by Pleskov [37], both the emitter and the collector were replaced by electrolytes, a thin semiconductor electrode thus forming the base of a transistor in which the base/emitter and the base/collector junctions were constituted by semiconductor/electrolyte junctions However, a major step forward came with the introduction of another type of transistor, namely the ISFET Speaking in terms of the scheme in Fig 1, this improvement was accomplished by going from ES and E1S structures to EIS structures

\section{(vi) Semiconductors and oxides in contact with gases}

From the beginning of semiconductor research the influence of gaseous ambients on the semiconductor surface properties has been a subject of investigation Earlier examples of these are studies of the reversible water adsorption and desorption on etched germanium surfaces by Brattain and Bardeen (the Brattain-Bardeen cycle, [38]) and of the influence of humidity on the behaviour of pn-junctions in silicon covered with a thick oxide layer by Shockley et al [39] In retrospect, it is surprising that the development of CSSDs was not taken up at that time 
In this case too it is meaningful to classify the sensor structures according to the nature of the insulating film on the semiconductor

By omitting the gate electrode of a MOSFET, Johannessen created a gas sensing device called the OGFET (Open Gate Field Effect Transistor), the physics and chemistry of this device were more intensively studied by Thorstensen [40] The device shows sensitivity to a number of gases such as the vapours of water, alcohols, benzene and carbon tetrachlonde

In Charge Flow Transistors (CFTs), developed and applied for chemical sensing by Senturia [41], part of the gate metal of a MISFET is replaced by a poorly conducting film, which may interact with its gaseous environment and thus be applied as a chemical sensor Also, its sensitivity to ions in an electrolyte could be investigated, then, the device is no longer operated in its GIS, but in its EIS mode

A gas sensing device called the Adsorption Field Effect Transistor (ADFET) was patented by Cox [42] in 1974 It 1s a FET-like structure with its extremely thin $(<5 \mathrm{~nm})$ gate oxide directly exposed to a gaseous environment, its fast and reversible response to a diversity of polar gases may be enhanced by suitable chemical surface modifications The response disappeared for devices with $20 \mathrm{~nm}$-thick gate oxides It is likely that simple adsorption/desorption reactions are the main operation principle of this device

The Surface Accessible Field Effect Transistor (SAFET, [43]) is very much like the ADFET Whereas in the ADFET the gate metal is completely omitted and the device thus operates with a floating gate potential, in the SAFET a polysilicon electrode is placed a short distance above the extremely thin oxide film, thus properly defining the electric field So far only the response to water, acetone and alcohols has been shown experimentally, but extensions as with the ADFET should be possible

It is obvious that the ADFET and the SAFET are GiS-CSSDs

Compound semiconductors are becoming increasingly popular as gas sensors Generally they are brought directly into contact with a gaseous environment without the interference of a thin insulating layer as with sllicon, and they thus belong to the class of GS-CSSDs Usually the conductance of a homogeneous semiconducting layer is measured as a function of environmental parameters with two electrodes, $\mathrm{SnO}_{2}$ and $\mathrm{ZnO}$ in particular are intensively studied Homogeneous semiconducting gas sensors have recently been reviewed by Helland [44] and Morrison [45]

\section{Results in related physicochemical experiments}

The generality of the scheme presented here also allows other physicochemical phenomena to be classified in XYS-systems Some relevant examples will be presented 
(1) EIS systems, first example

In their studies of the $\mathrm{S} 1 / \mathrm{SiO}_{2}$ electrode, Madou et al [46] describe the electrical conducting properties of $\mathrm{SiO}_{2}$ layers that have previously been 'activated' by a thermal or electrochemical treatment resulting in electron transfer reactions at the $\mathrm{SiO}_{2}$ /electrolyte interface, they suggest the use of these structures as 'a new class of FET-based sensors sensitive to redox couples'

\section{(ii) EIS systems, second example}

Wolken berg [47] studied EIS systems, but with the purpose of investigating the properties of the $\mathrm{S} / \mathrm{SlO}_{2}$ interface Although MIS-devices are more often used in that kind of experiments, no fundamental objections can be raised against an electrochemical approach, as is in accordance with our scheme

\section{(lil) ElS systems}

In the same paper [47] Wolkenberg calculated and experimentally determined the current-voltage characteristics of E1S systems with a 20 $22 \mathrm{~nm}$ oxide layer on silicon, the results turn out to be quite analogous to those for MiS systems

\section{(iv) GiS systems}

Interesting physicochemical phenomena involving silicon-thin oxıdegas structures are reported by Caplan et al [48] When irradiated with u v light in the presence of oxygen, the so called $\mathrm{P}_{\mathrm{b}}$-centres $\left(\mathrm{Si}_{3} \equiv \mathrm{S} 1\right.$-groups at the $\mathrm{S} 1 / \mathrm{SlO}_{2}$ interface) are depopulated, as monitored by a decrease in their ESR signal Optically-induced electron transfer from the $\mathrm{P}_{\mathrm{b}}$-centres to adsorbed oxygen molecules, thereby forming $\mathrm{O}_{2}^{-}$-molecules and ESRinvisible $\mathrm{Sl}_{3} \equiv \mathrm{Sl}^{+}$groups, is suggested as an explanation for this phenomenon In the reverse effect electron tunneling through the thin oxide layer may be involved These phenomena occur exclusively for thin, $\imath e$, less than $5 \mathrm{~nm}$, oxide layers

\section{Concludıng remarks}

Of course, CSSDs may be divided into groups or classes in many different ways, e g, according to the principle of their electronic operation (capacitive, resistive, are the devices transistors, diodes or simply resistors?) or the principle of their chemical operation (which species is actually involved in the physicochemical part of the sensing? is the sensing reaction reversible? which surfaces or interfaces play a role?)

We feel that in the scheme presented here, many of the above considerations are accommodated in a reasonable fashion In addition, the scheme is very general, allowing related fields of investigations to be included as well

The devices discussed in this paper are called chemically sensitive sem1conductor devices, but in most cases the semiconductor is merely involved in 
the electronic part of the sensing process, $l e$, its ability to form modifiable surface- or space-charge layers is used Only in the case of the semiconductor-electrolyte (ES) and semiconductor-gas (GS) systems is the semiconductor itself involved in the physicochemical part of the sensing process

\section{Acknowledgements}

The authors are indebted to professor Dr $M J$ Sparnaay and $\operatorname{Dr} A$ van Sifhout of the solid state physics department for their continuous and stimulating interest in these studies

These investigations in the programme of the Foundation for Fundamental Research on Matter (FOM) have been supported by the Foundation for Technical Research (STW), future Technical Science Branch/Division of the Netherlands Organization for the Advancement of Pure Research (ZWO)

\section{References}

1 S M Sze, Physics of Semiconductor Devices, Wiley, New York, 1969

2 A Wolkenberg, Energetic barrier height hypothesis on the silicon-electrolyte and gallium arsenıde-electrolyte interfaces, Phys Status Solıdl (a), 50 (1978) 249 - 256

3 V A Myamlın and Y V Pleskov, Electrochemistry of Semiconductors, Plenum Press, New York, 1967

4 See Surf Scl, 101 (1980)

5 (a) I Lundstrom, M S Shivaraman and C Svensson, A hydrogen sensitive Pd-gate MOS transistor, $J$ Appl Phys, 46 (1975) 3876 - 3881

(b) I Lundstrom, M S Shivaraman and C Svensson, Chemical reactions on palladium surfaces studied with Pd-MOS structures, Surf Sct, 64 (1977) 497 - 519

6 D Krey, $\mathrm{K}$ Dobos and G Zimmer, An integrated CO-sensitive MOS transistor, Sensors and Actuators, 3 (1983) 169 - 177

7 (a) J P Coupot, B Cornut and C Chambu, A reversible hydrogen sulphide sensitive Pd-gate MOS transistor, Proc Int Meet on Chem Sens, Fukuoka, Japan, Elsevier, Amsterdam, 1983, p 468

(b) M S Shivaraman, Detection of $\mathrm{H}_{2} \mathrm{~S}$ with Pd-gate MOS field-effect transistors, $J$ Appl Phys , 47 (1976) 3592 - 3593

8 (a) A Spetz, F Winquist, C Nylander and I Lundstrom, Modified palladium-gate MOS devices for ammonia gas detection, Proc Int Meet on Chem Sens, Fukuoka, Japan, Elsevier, Amsterdam, 1983, p 479

(b) See ref $5 a$

$9 \mathrm{M}$ Armgarth, Physics of palladium metal-oxide-semiconductor devices, Thesis, Linkoping, Sweden, 1983

10 G A Corker and C M Svensson, Sodium-induced work function shift of mercury as a metal-oxıde-semiconductor electrode, $J$ Electrochem Soc, 125 (1978) 1881 1883

11 J N Zemel, B Keramatı and C W Spıvak, Non FET chemıcal sensors, Sensors and Actuators, 1 (1981) 427 - 474

12 M Duszak, A Jakubowskı and W Sekulski, A chemically sensitive MOS element with an ultrathin dielectric film, Thin Solld Films, 75 (1981) 379 - 382

13 S J Fonash, $H$ Huston and $S$ Ashok, Conducting MIS diode gas detectors the $\mathrm{Pd} / \mathrm{S}_{1} \mathrm{O}_{x} / \mathrm{S} 1$ hydrogen sensor, Sensors and Actuators, 2 (1982) 363 - 369 
14 A D'Amico, G Fortunato, G Petrocco and G Coluzza, Pd/a-Si H metal-insulatorsemiconductor Schottky barrier diode for hydrogen detection, Appl Phys Lett, 42 (1983) $964-965$

$15 \mathrm{~K}$ Ito, Hydrogen sensitive Schottky bamer diodes, Surf Sct, 86 (1979) $345-352$

$16 \mathrm{M} \mathrm{C}$ Steele and B A MacIver, Palladium/cadmum sulphide Schottky diodes for hydrogen detection, Appl Phys Lett, 28 (1976) $687-688$

$17 \mathrm{~N}$ Yamamoto, $\mathrm{S}$ Tonomura, $\mathrm{T}$ Matsuoka and $\mathrm{H}$ Tsubomara, A study on a Pd-titanlum oxıde Schottky diode as a detector for gaseous components, Surf Sct, 92 (1980) $401-406$

18 K Ito, Hydrogen sensitive photodiode, Proc 2nd Sensor Symp Japan, 1982, p 205

19 I Lundstrom, Hydrogen sensitive MOS structures, Part 1 Principles and applications, Sensors and Actuators, 1 (1981) $403-426$

$20 \mathrm{~J}$ Janata and $\mathrm{R} J$ Huber, Ion sensitive field effect transistors, Ion Select Electrode Rev, 1 (1979) $31-79$

21 I Lauks, Polarizable Electrodes, Part II, Sensors and Actuators, 1 (1981) 393 - 402

$22 \mathrm{~W} M$ Siu and $\mathrm{R} S \mathrm{C}$ Cobbold, Basic properties of the electrolyte-SiO $\mathrm{S}_{2}-\mathrm{Si}_{1}$ system physical and theoretical aspects, IEEE Trans Elect Dev, ED-26 (1979) 1805 - 1815

$23 \mathrm{~L} \mathrm{~J}$ Bousse, The chemical sensitivity of electrolyte/msulator/silicon structures, Thesis, Enschede, The Netherlands, 1982

$24 \mathrm{~T}$ Matsuo and $\mathrm{M}$ Esash, Methods of ISFET fabrication, Sensors and Actuators, 1 (1981) $77-96$

25 (a) P J Holmes (ed ), The Electrochemistry of Semiconductors, Academic Press, London, 1962

(b) See ref 5

(c) $\mathrm{H}$ Gensher, Semiconductor electrode reactions, Adv Electrochem Electrochem Eng, 1 (1961) $139-232$

(d) $\mathbf{R}$ Memming, Charge transfer processes at semiconductor electrodes, Electroanal Chem, 11 (1979) 1-84

(e) S $\mathbf{R}$ Morrison, Electrochemistry at Semiconductor and Oxtdized Metal Electrodes, Plenum, New York, 1980

26 W H Brattain and G C B Garrett, Experiments on the interface between german!* um and an electrolyte, Bell Syst Tech $J, 34$ (1955) $129-175$

$27 \mathrm{G}$ Brouwer, Control of the surface potential of germanum by means of a variable pH electrolyte containing hydrogen peroxide and potassium chloride, $J$ Electrochem Soc, $114(1967) 743 \cdot 748$

$28 \mathrm{M} J$ Sparnaay, The interaction between germanium and cupric ions in an aqueous solution, Surf Scl, 1 (1964) $102 \cdot 109$

$29 \mathrm{~W} H$ Brattain and $P \mathrm{~J}$ Boddy, Interaction of lodide ion with germanium electrodes, Surf Scl, 4 (1966) 18 - 32

30 M J Madou, B H Loo, $K$ W Frese and S $R$ Morrison, Bulk and surface character1zation of the silicon electrode, Surf Sct, 108 (1981) $135-152$

$31 \mathrm{~J} N$ Chazalviel, Schottky barrer height and reverse current of the $\mathrm{n}$-Si-electrolyte junction, Surf $S c t, 88$ (1979) $204-220$

32 A A Saaman and $P$ Bergveld, to be published

$33 \mathrm{~K}$ Kinoshita and $\mathrm{M}$ J Madou, Electrochemical measurements on $\mathrm{Pt}, \mathrm{Ir}$ and $\mathrm{T}_{1}$-oxudes as pH probes, $J$ Electrochem Soc, 131 (1984) $1089-1094$

34 D S Ginley and M A Butler, Flatband potential of cadmium sulphide (CdS) photoanodes and its dependence on surface ion effects, $J$ Electrochem Soc, 125 (1978) $1968 \cdot 1974$

$35 \mathrm{~N} F$ de Rooy and $P$ Bergveld, The iridium/anodic indium oxıde film electrode as a pH-sensor, In H P Kimmich, (ed ), Monttoring of Vital Parameters durng Extracorporal Circulation, Karger, Basel, 1981, pp $156-165$

36 L Cammill, L Alcidi, G Papeschı, V Wiechmann, L Padeletti and G Grassı, Prelıminary expenence with the pH-tnggered pacemaker, Pace, 1 (1978) $448-457$

37 See ref $3, \mathrm{p} 214$ 
$38 \mathrm{~W}$ H Brattain and $J$ Bardeen, Surface properties of germanium, Bell Syst Tech $J$, 32 (1953) $1-41$

39 W Shockley, W W Hooper, H J Queisser and W Schroen, Mobile electric charges on insulating oxides with application to oxide covered silicon p-n junction, Surf Scz, 2 (1964) $277-287$

40 B Thorstensen, Field effect studies of gas adsorption on oxidized silicon surfaces, Thests, Trondheim, Norway, 1980

41 (a) S D Senturia, S M Sechen and J A Wishneusky, The charge-flow transistor A new MOS-device, Appl Phys Lett, 30 (1977) $106-108$

(b) S D Senturia, M G Huberman, $R$ Van der Kloot, Moisture sensing with the charge flow transistor, Nat Bur Stand (US) Spec Publ 40069, 1981, pp 108114

$42 \mathrm{P} F$ Cox, Environment monitoring device and system, US Pat 3831432,1974

43 M Stenberg and B I Dahlenback, Surface-accessible FET for gas sensing, Sensors and Actuators, 2 (1982) $363 \cdot 369$

44 G Helland, Homogeneous semiconductıng gas sensors, Sensors and Actuators, 2 (1982) $343-361$

45 S $R$ Morrison, Semiconductor gas sensors, Sensors and Actuators, 2 (1982) 329 341

46 (a) M J Madou, $K$ W Frese and S R Morrison, The silicon/silica electrode, Phys Stat Sol (a), 57 (1980) $705-712$

(b) $\mathrm{S} R$ Morrison, $\mathrm{M} J$ Madou and $\mathrm{K}$ W Frese, Imperfections in and ion diffusion through oxıde layers on silicon, Appl Surf Scı, 6 (1980) $138-148$

47 A Wolkenberg, Trapping properties of the silicon-silicondioxide interface from electrochemical current-voltage behaviour, Appl Surf Sci, 2 (1979) 502 - 513

$48 \mathrm{Ph} J$ Caplan, E H Poindexter and S R Morrison, Ultraviolet bleaching and regeneration of $\mathrm{S}_{1} \equiv \mathrm{S}_{3}$ centres at the $\mathrm{S}_{1} / \mathrm{SiO}_{2}$ interface of thinly oxidized silicon wafers, $J$ Appl Phys, 53 (1982) $541-545$

\section{Biographies}

Ary Saaman was born in Nijmegen, the Netherlands, on June 1, 1959 He recelved his M S degree in chemistry from the University of Nijmegen in 1983 (with honours) Since then he has been working on a project on chemical sensors at the Twente University of Technology, Enschede, the Netherlands $\mathrm{He}$ is interested in the fundamental physics and (electro)chemistry of semiconductors and the application of semiconductors in solar energy conversion and chemical sensors

Plet Bergueld was born in Oosterwolde, the Netherlands, on January 26, $1940 \mathrm{He}$ recelved the $\mathrm{M} \mathrm{S}$ degree in electrical engineering (electronics) from Eindhoven University of Technology, Eindhoven, the Netherlands, in 1965, and the Ph D degree from Twente University of Technology, Enschede, the Netherlands, in 1973

Since 1965 he has been a member of the Bio-information Group, Department of Electrical Engineering, Twente University of Technology He is also a member of the Coordination Centre for Biomedical Engineering and a member of the Research Unit Sensors and Actuators of this University In 1981 he became a member of the Semiconductor Group of the Foundation for Fundamental Research on Matter in the Netherlands 
The subject of his dissertation was the ion-sensitive field-effect transistor (ISFET) and the OSFET $\mathrm{He}$ is involved in research on electronic measuring and stımulating methods in physiological systems, with special attention for in vivo biosensors He lectures on biomedical instrumentation for graduate students of Twente University of Technology and medical personnel of afflliated hospitals

In 1984 he was appointed as full professor in biosensor technology at the Twente University of Technology 